\title{
Application of Computer Support for Design of Shaft Furnaces - Cupolas
}

\author{
Grzegorz Dajczer ${ }^{a^{*}}$, Rafał Dańko ${ }^{\mathrm{b}}$ \\ aKPR PRODLEW-KRAKÓW Spółka z o.o., Alfreda Dauna 78, 30-629 Krakow, Poland \\ ${ }^{\mathrm{b}}$ AGH University of Science and Technology, Faculty of Foundry Engineering, Reymonta 23, 30-059 Krakow, Poland \\ *e-mail: peruar@poczta.fm
}

Received: 12 October 2017/Accepted: 13 December 2017/Published online: 31 January 2018

This article is published with open access at AGH University of Science and Technology

\begin{abstract}
:
Designing a machine's constructions and an object's structures is one of the areas of technology design. The complexity of the structure is defined by the technology for which it is used. Following the theory of construction and mechanisms, the full characteristics of a machine or device is defined by its shape and operating parameters. The shape reflects geometry. As a result of using the correct parameters, the construction should functional correctly (which means according to its general principles of operation).

The project of any structure is a creative process performed by a team of designers and constructors. The contemporary design is not solely based on the personal preferences of engineers. More and more scientific and computerized design methods are being introduced to this process. They are characterized as computer-aided systems and are based on algorithms, programs, and IT equipment.

This article presents the methodological application of computer-aided design on an example of the design of shaft furnaces that are used in foundries as cast iron smelters. These furnaces, called cupolas, have again become objects of interest for research. In the design of the cupola construction, Autodesk Inventor techniques were used.
\end{abstract}

\section{Keywords:}

cupola design, cupola, design, projects, design process

\section{INTRODUCTION}

Designing a machine's constructions and an object's structures is one of the areas of technology design. The complexity of the structure is defined by the technology for which it is used. Following the theory of construction and mechanisms, the full characteristics of a machine or device is defined by its shape and operating parameters. The shape reflects geometry. As a result of using the correct parameters, the construction should functional correctly (which means according to its general principles of operation).

The project of any structure is a creative process performed by a team of designers and constructors. The contemporary design is not solely based on the personal preferences of engineers. More and more scientific and computerized design methods are being introduced to this process. They are characterized as computer-aided systems and are based on algorithms, programs, and IT equipment [1].

This article presents the methodological application of computer-aided design on an example of the design of shaft furnaces that are used in foundries as cast iron smelters. These furnaces, called cupolas, have again become objects of interest for research. In the design of the cupola construction, Autodesk Inventor techniques were used.

\section{METHODOLOGY OF COMPUTER-ASSISTED PROCESS}

The methodology indicates the course of the construction process, which is required by the general theory of systems. The result of the presented methodology is the project. According to the definition, the design takes the form of a drawing, descriptive and computational form. Result of this process is a geometrical form of the designed object. The main objective in the presented method is the drawing, and the mentioned input and output parameters were defined by technological dependencies. The result of this process is a geometrical form of the designed object.

According to the theory, each object is treated as a defined construction consisting of parts that have varying degrees of complexity. The components form the structure of the whole construction. They are integrated based on common relationships. These relationships are represented by the input and output parameters. The proposed methodology demonstrates the complex construction of a cupola that consists of specific parts. 


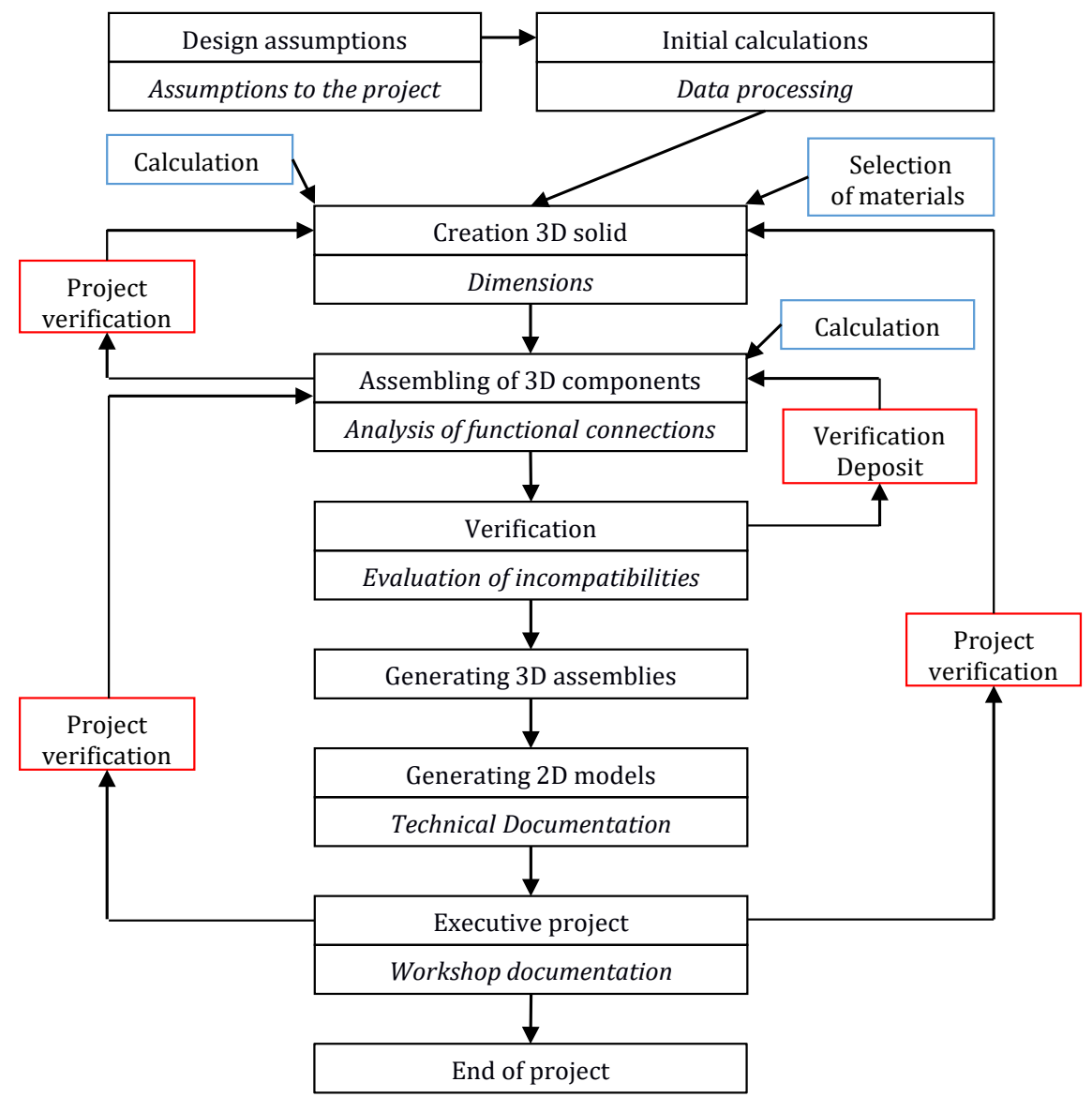

Fig. 1. Methodology of computer-assisted process

The construction of each part is confirmed by calculations of the melting and exploitation processes. The essence of the methodology is shown in Figure 1.

\section{ESSENCE OF PROGRAMS USED}

The dynamic development of information technology as well as information systems have resulted in the fact that many programs that facilitate the solving of technological, constructional, and organizational planning have appeared on the market [2].

Currently, the process of creating programs has shown dynamic development. Among a number of available tools, programs that create geometry and perform basic calculations are considered to be part of the structural design family. Such programs as Catia, ProEngineer, Solid Works, Auto Desk Inventor, and Solid Edge are considered the leading ones.

The main feature of these programs is the freedom of modeling lumps of elements and assemblies of elements with varying degrees of complexity. One of the requirements for the programs is input information, which can be analytically written as well as in the form of simplified diagrams.

An essential condition for using the programs is to secure the proper IT equipment. A computer needs to be selected to be compatible with the software. Additionally, the ability to print documentation is crucial. Figures 2 and 3 show a geometrical shape with optimal features and basic geometric figures used for designing the final model.

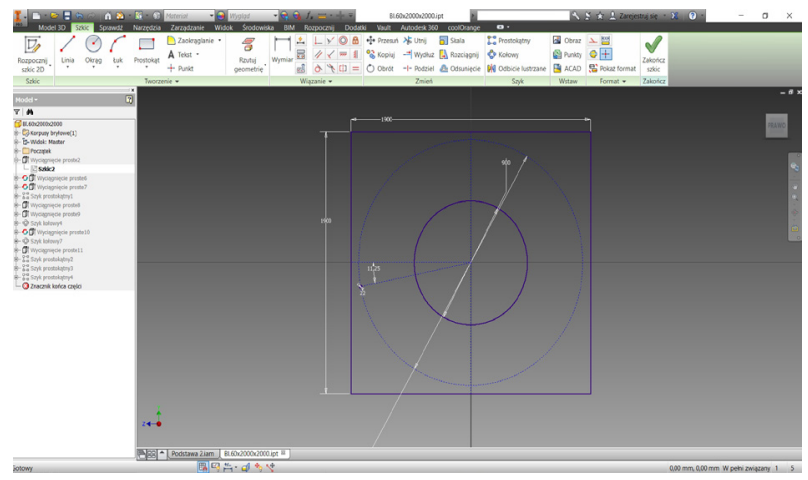

Fig. 2. Print screen from modeling process

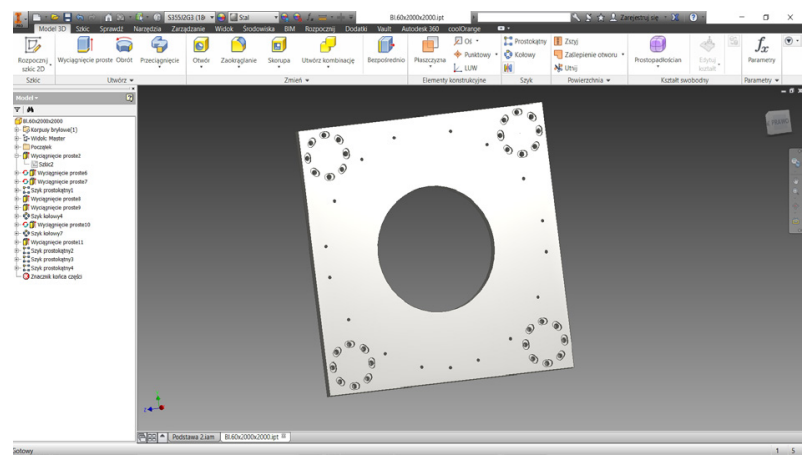

Fig. 3. Print screen from modeling process of basic shape in sequence: basic shape, point and Edge, free movement, fitting of solid to end shape 
In the next step, verification of the parameters describing the geometry of the structure is carried out on a sketch of the mechanical system (Fig. 4).

The final stage is the process of creating a 3D assembly structure. This is a procedure that checks the connections of the components in the spatial layout (Fig. 5).

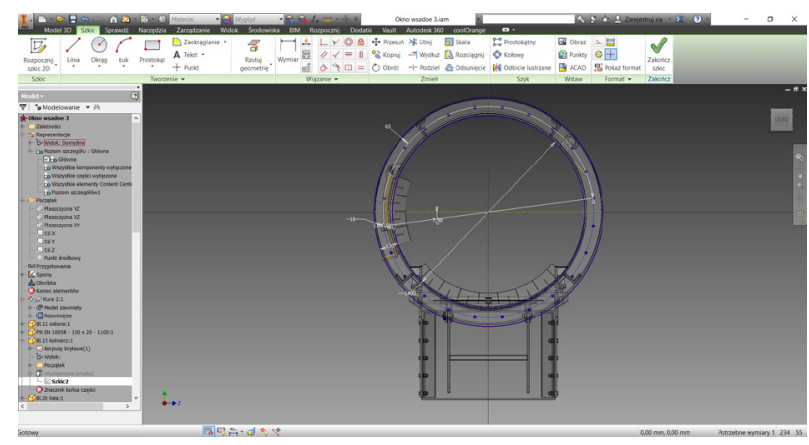

Fig. 4. Print screen from verification and eliminating discrepancies

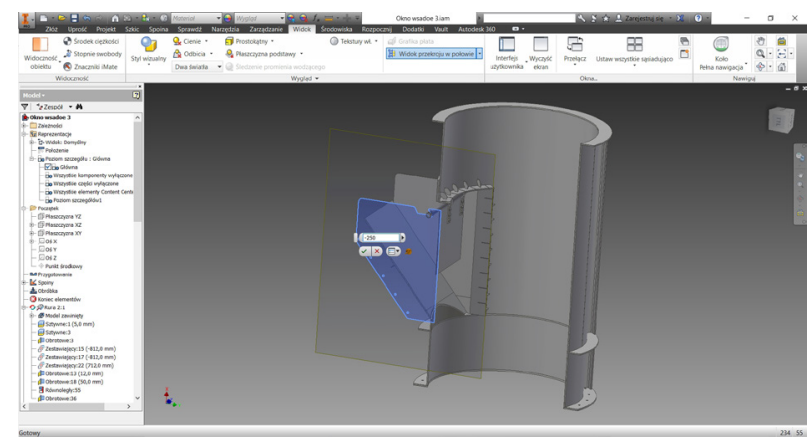

Fig. 5. Example of 3D construction

\section{DESIGN AND CONSTRUCTION ASSUMPTIONS}

The design and construction assumptions are based on the requirements of the casting program and, in particular, on the demand for the liquid metal. This quantity depends on the performance of the furnace.

There is a close relationship between the amount of metal-yielded melting and the furnace construction. This is determined by the theory of coke combustion (fuel) and melting of a feedstock that is composed of metallic materials and fluxes. Schematically, this relationship - the diameter of the main part of the cupola is shown in Figure 6 [3].

For an easy construction process, engineers very often use diagrams that omit complicated formulas. The ability to use the diagram (Fig. 7) [4] enables them to read the data needed for subsequent assumptions of the design and construction processes.

Another position facilitating the design of the cupola construction is the size that determines the level of a batch window. This value is assumed to be a factor of between an 8 to 10 active cupola diameter. This coefficient was determined experimentally [3]. For example, for a diameter of $d=850 \mathrm{~mm}$, the window level is $7.5 \mathrm{~m}$. The determined level of the window affects the total height of the furnace. The end of the construction is the chimney part of the cupola consisting of a carbon monoxide post-combustion chamber, a recuperator, and a wet duster.

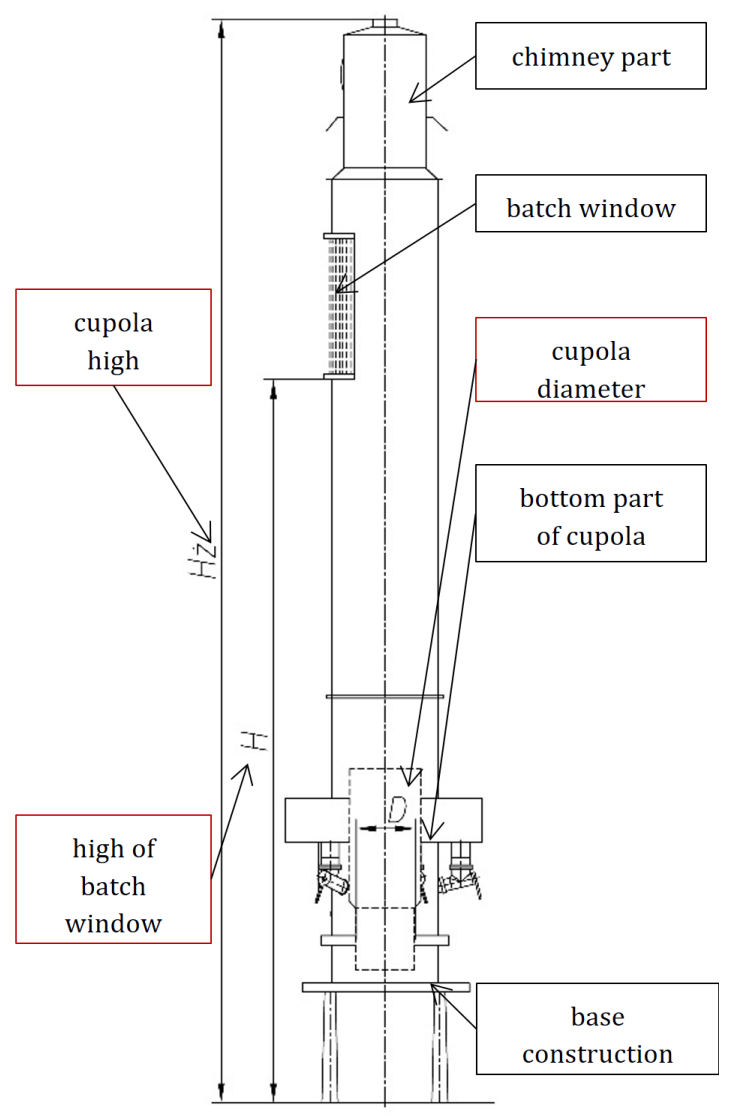

Fig. 6. Schematic picture of cupola [3]

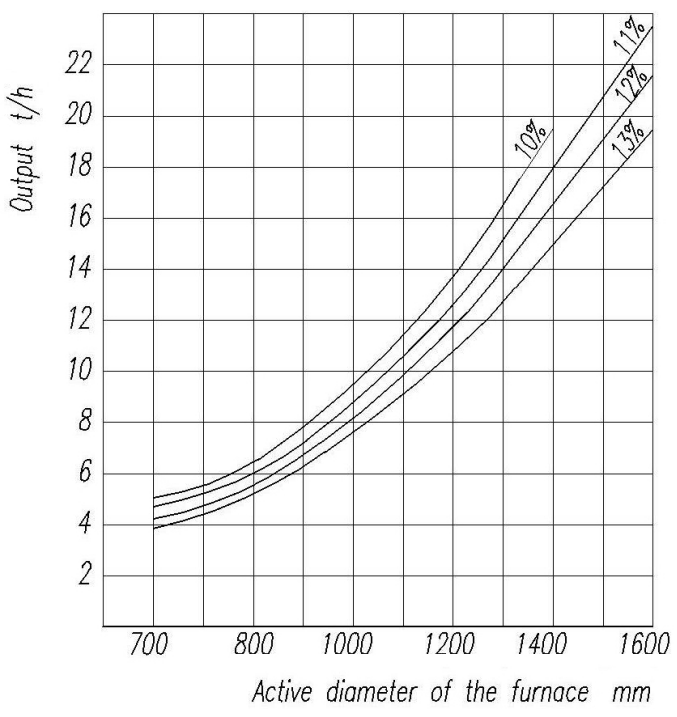

Fig. 7. Efficiency of cupola depends on size of furnace and distribution of coke at blowing temperature of $450^{\circ} \mathrm{C}$ [4]

For operational reasons, the entire structure should rest on a stable foundation, which is designed using static calculations. The list of elements that have been proposed for the chosen methodology is shown in Figure 8 [5]. In addition, peripheral installations (e.g., installation of cupola cooling, air blasting) are added. The effectiveness and safety during the melting process depend on them.

The final result of the procedure used is the cupola construction is shown in Figure 9. 
a)

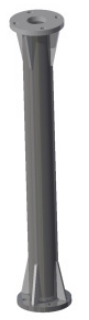

e)

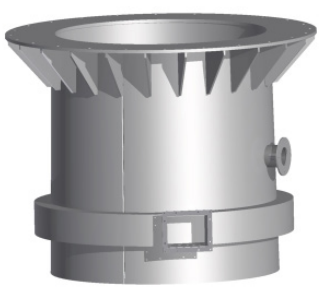

b)

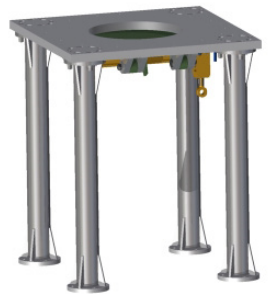

f)

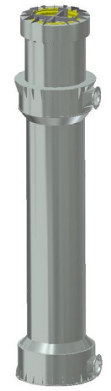

c)

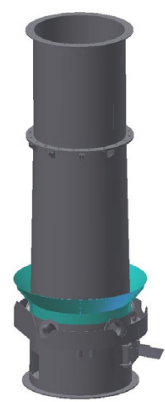

g)

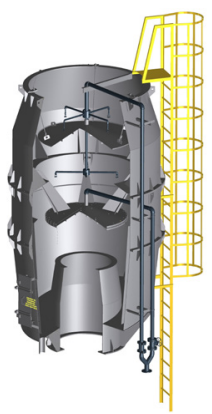

Fig. 8. Collection of cupola's construction parts: a) column; b) base; c) bottom part of cupola; d) batch window; e) chimney part of afterburner carbon monoxide; f) recuperator; g) wet duster [5]

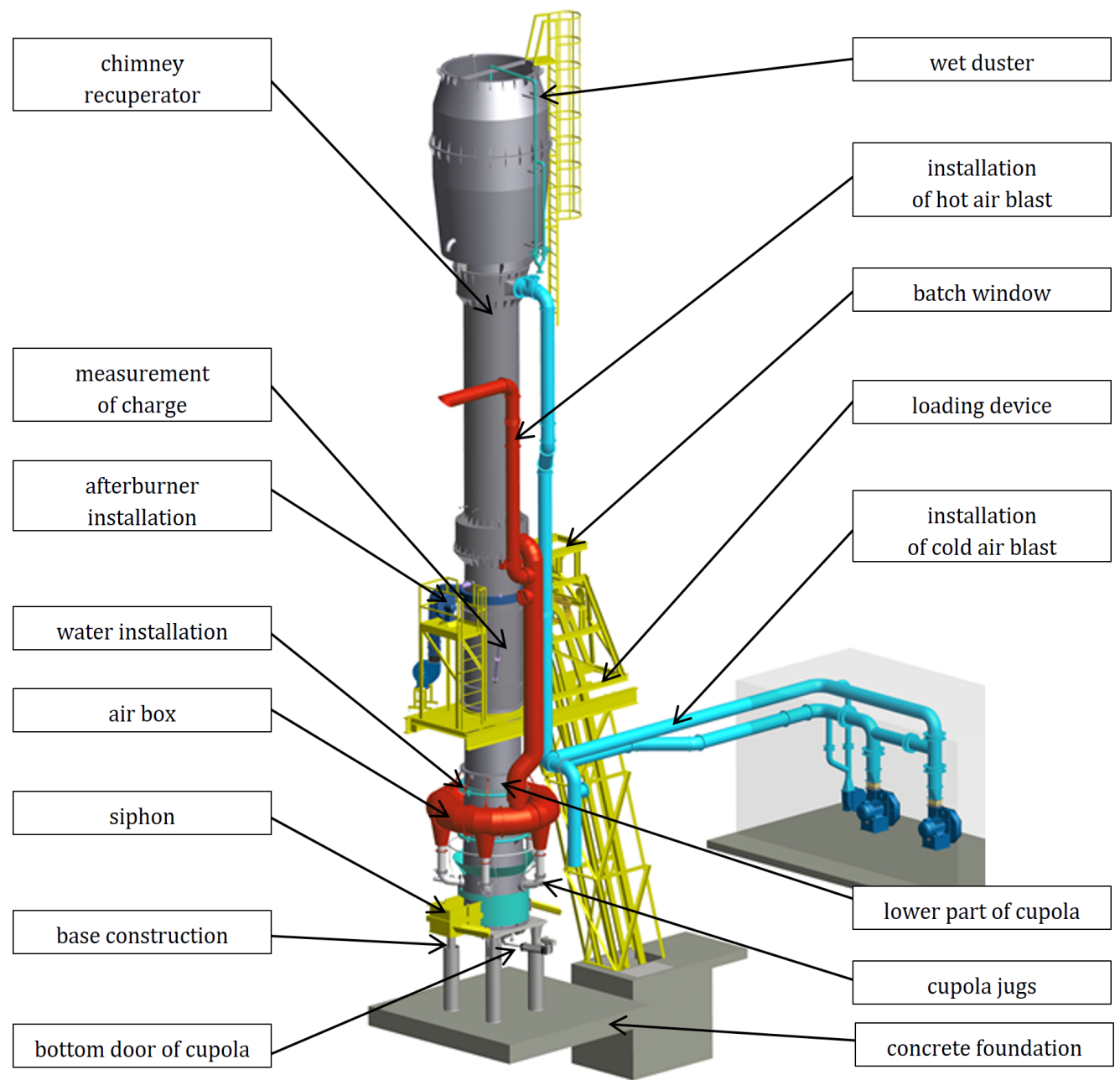

Fig. 9. Elements of shaft furnace designed in process of sequence construction. Design of cast iron with hot air blast presenting all components [5] 


\section{SUMMARY}

The methodology of structural design using computer-aided systems helps us to seek rational solutions with optimal characteristics.

A confirmation of this thesis is shown in the methodology presented in the article that includes design assumptions as an input element.

Additionally, the use of computer programs helps us to easily generate the design documentation necessary in the process of performing a construction in a material. The demand for materials as well as the assembly process are based on such documentation.

The presented construction of the cupola is a prototype construction that was successfully implemented in one of the Polish foundries. The cupola shaft was tested under production conditions. The good melting result indicates that the methodology of designing this furnace was correct.

\section{REFERENCES}

[1] Wrona R., Stawowy A. \& Macioł A. (2006). Podstawy inżynierii projektowania odlewni. Kraków: Pandit.

[2] Autodesk. Autodesk Inventor 2015, software and tools applied to create cupola project.

[3] Podrzucki C. \& Szopa J. (1983). Piece i urządzenia metalurgiczne stosowane $w$ odlewnictwie. Katowice: Wydawnictwo "Śląsk".

[4] Prodlew Oddział Kraków (1971). Wskaźniki technologiczne topialni (project). Kraków.

[5] KPR Prodlew-Kraków Sp. z o.o. (2006). Project of cupola ø850 with chimney heater to reduce coke consumption. Kraków. 